\title{
Oportunidades de visitação oferecidas em Áreas Naturais Protegidas: análise dos Parques Nacionais mais visitados no Brasil e nos Estados Unidos da América em 2017
}

\author{
Recreational opportunities offered in Protected Natural Areas: analysis of \\ the most visited National Parks in Brazil and the United States of America \\ in 2017
}

\author{
Carolina Ribeiro Gomes ${ }^{1}$ (10) \\ Múcio do Amaral Figueiredo 2 \\ Geraldo Majela Moraes Salvio ${ }^{3}$
}

\begin{abstract}
Palavras-chave:
ROS

Plano de Gestão

Turismo

Resumo

Parques Nacionais (PN) são estratégias de proteção da natureza e realização da atividade turística que demandam ferramentas para visitação adequada. Com o avanço do turismo nestas áreas, os PN assumem dupla responsabilidade: manter a qualidade da experiência dos visitantes e contribuir com todo seu potencial para sociedade. Nesse sentido, a ferramenta Recreation Opportunity Spectrum (ROS) categoriza as denominadas "Oportunidades de Visitação" em diferentes classes (Prístina, Primitiva, Natural, Rural e Urbana) para identificar atributos específicos para cada ambiente e público, organizando o turismo. Neste cenário, o objetivo foi analisar as oportunidades oferecidas em 10 Parques Nacionais, cinco no Brasil e cinco nos Estados Unidos da América e entender como as diferentes Classes de Oportunidades podem influenciar a visitação turística. Os dados foram obtidos a partir de pesquisa bibliográfica e documental. Identificado os potenciais turísticos de cada PN, aplicou-se a metodologia ROS. Os resultados mostraram que existe relação entre o número de oportunidades oferecidas e o número de visitantes que o Parque Nacional recebe, confirmando o pressuposto que, tanto nos Parques brasileiros quanto estadunidenses, diferentes oportunidades recreativas relaciona-se ao maior número visitantes. Dessa forma, a ferramenta Recreation Opportunity Spectrum apresenta-se como importante ferramenta de gestão da visitação turística. A possibilidade de criar classes de visitação em áreas naturais deve ser amplamente utilizada para garantir o turismo sustentável.
\end{abstract}

\section{Keywords:}

ROS

Management Plan

Tourism

\footnotetext{
${ }^{1}$ Universidade Federal de São João del-Rei, São João del-Rei, MG, Brasil. carolrggomes@gmail.com ${ }^{2}$ Universidade Federal de São João del-Rei, São João del-Rei, MG, Brasil. muciofigueiredo@ufsj.edu.br

${ }^{3}$ Instituto Federal de Educação, Ciência e Tecnologia do Sudeste de Minas Gerais, Barbacena, MG, Brasil. geraldo.majela@ifsudestemg.edu.br
} 


\section{INTRODUÇÃO}

No contexto da política de estabelecimento das Áreas Protegidas (AP), no Brasil, os Parques Nacionais (PN), importantes estratégias de proteção da natureza e desenvolvimento turístico, se tornaram a categoria de espaço protegido mais conhecida e tradicional (DRUMMOND et al., 2010; CUNHA; SPINOLA, 2014; PIRES; RUGINE, 2018), sendo incluída em Sistemas de Áreas Protegidas no mundo todo, com destaque para países da Europa e Américas (MENEGUEL; ETCHEBEHERE, 2011; SALVIO; GOMES, 2018).

Segundo a União Internacional para a Conservação da Natureza (IUCN, 2019), Parque Nacional tem como objetivo de manejo proteger a biodiversidade natural, os ecossistemas, suas estruturas ecológicas e seus processos ambientais, além de promover a educação ambiental, recreação e pesquisas.

Com o avanço do turismo nestas áreas, os PN assumem dupla responsabilidade: manter a qualidade da experiência dos visitantes e contribuir com todo seu potencial para sociedade, uma vez que geram benefícios tanto econômicos como intangíveis, como aqueles oriundos do turismo, os serviços prestados pelos ecossistemas (ar puro, água limpa e ciclagem geoquímica natural), os intangíveis, relacionados ao próprio valor intrínseco da natureza, e o bem-estar físico das atividades nestes locais (TERBORGH; SCHAIK, 2002).As experiências de alta qualidade vividas pelos visitantes nesses locais despertam o apoio dos próprios turistas na conservação do meio ambiente (MANNING, 2002).

Diversos estudos (BROWN et al., 1978; CLARK; STANKEY, 1979; TAKAHASHI, 2004; BROWN et al., 2005; ICMBIO, 2011b; COELHO, 2015; ICMBIO, 2018a) confirmam que não existe um "visitante típico", com perfil médio que procuram por uma atividade específica, mas buscam ambientes e experiências diversificadas a fim de suprir suas expectativas. Dessa forma, a oferta de diferentes oportunidades e ambientes satisfaz uma demanda de públicos diversificada. Cada visitante é motivada(o) a escolher um ambiente segundo suas necessidades e expectativas, as quais são atendidas de acordo com o que é oferecido pela AP, tais como turismo de aventura, ecoturismo, geoturismo, entre outros.

Nesse sentido, a importância da aplicação do Recreation Opportunity Spectrum (ROS), o qual define zonas específicas, denominadas "Classes de Oportunidades" (Prístina, Primitiva, Natural, Rural e Urbana), está na capacidade de categorizar cada zona, desde aquelas consideradas primitivas àquelas que já sofreram alguma intervenção, para identificar as atividades específicas adequadas para cada área e para cada público, conciliando a qualidade da experiência da visita com os objetivos de conservação, e no desenvolvimento de planos de gestão para administrar e oferecer diferentes oportunidades (BROWN et al., 1978; CLARK; STANKEY, 1979; ORMSBY et al., 2004; BROWN et al., 2005; ICMBIO, 2011b; ICMBIO, 2018a).

As oportunidades de visitação são formadas a partir da relação entre as atividades, o ambiente (atributos biofísicos, socioculturais e de manejo), a experiência potencial e os benefícios gerados (DRIVER; BROWN, 1978). A junção de todos esses fatores, sejam cenários e ambientes propícios a visitação, atrativos e atividades turísticas, tipos de acessos, serviços de hospedagem e alimentação, nível de infraestrutura, presença institucional, entre outros, variam em cada classe do espectro. As classes são desenhadas conforme o aumento intensivo do uso de acordo com aspectos naturais, sociais e de gestão (atributos do ROS). Cada ambiente, dentro da AP, resulta da combinação de diversas experiências, para diferentes tipos de visitantes. $\mathrm{O}$ espectro favorece essa diversidade a nível adequado de proteção e utilização dos recursos e atrações turísticas (LEE et al., 2013).

Dessa forma, este estudo teve como objetivo compreender se os PN mais visitados do Brasil e dos Estados Unidos da América (EUA) são os que oferecem mais oportunidades recreativas.

\section{MATERIAIS E MÉTODOS}

\section{Caracterização dos Parques Nacionais estudados}

A pesquisa compõe-se pela análise de cinco $\mathrm{PN}$ mais visitados no Brasil e cinco mais visitados nos EUA, ambos referentes ao ano de 2017. Os Quadros 1 e 2 apresentam as características principais, e informações referentes ao uso público e as oportunidades de visitação. A Figura 1 apresenta a localização dos Parques Nacionais estudados, localizados no Brasil e nos Estados Unidos. 
Quadro 1 - Informações sobre os Cinco Parque Nacional Brasileiros estudados

\begin{tabular}{|c|c|c|c|c|}
\hline $\begin{array}{l}\text { PARQUE } \\
\text { NACIONAL }\end{array}$ & $\begin{array}{l}\text { BREVE CARACTERIZAČ̃̃ E E } \\
\text { LOCALIZAÇÃO GEOGRÁFICA }\end{array}$ & $\begin{array}{l}\text { ÁREA } \\
\text { TOTAL }\end{array}$ & $\begin{array}{l}\text { ANO DE } \\
\text { CRIAÇÃOO }\end{array}$ & $\begin{array}{l}\text { USO PÚBLICO E OPORTUNIDADES DE } \\
\text { VISITAÇÃO }\end{array}$ \\
\hline $\begin{array}{l}\text { Parque Nacional } \\
\text { da Tijuca }\end{array}$ & $\begin{array}{l}\text { Está localizado no centro da cidade do } \\
\text { Rio de Janeiro, nas montanhas do } \\
\text { Maciço da Tijuca, entre os paralelos } \\
22^{\circ} 55^{\prime} \mathrm{S} \text { e } 23^{\circ} 00^{\prime} \mathrm{S} \text { e os meridianos } \\
43^{\circ} 11^{\prime} \mathrm{W} \text { e } 43^{\circ} 19^{\prime} \mathrm{W} \text {, no centro sul do } \\
\text { estado do Rio de Janeiro (RJ). Possui } \\
\text { estrutura turística ampla e difundida } \\
\text { em três setores Floresta, Serra da } \\
\text { Carioca e Pedra Bonita/Pedra da } \\
\text { Gávea. As partes de floresta } \\
\text { separadas são interligadas por vias de } \\
\text { circulação e edificações. }\end{array}$ & $\begin{array}{l}3.95 \text { mil } \\
\text { hectares }\end{array}$ & 1961 & $\begin{array}{l}\text { Possui estrutura turística com mais de } 150 \\
\text { atrativos, } 128 \text { quilômetros de trilhas } \\
\text { manejadas para o uso público e } 52 \mathrm{~km} \text { de } \\
\text { estradas internas, além de } 69 \text { monumentos } \\
\text { históricos e um centro de visitantes. O Parque } \\
\text { possui áreas conservadas e áreas com alto } \\
\text { grau de intervenção e utilização turística } \\
\text { distribuídas em seus três setores. O } \\
\text { Corcovado é o principal atrativo visitado, } \\
\text { representando } 62 \% \text { do total, seguido da } \\
\text { Estrada da Vista Chinesa, com } 16 \% \text { e do Setor } \\
\text { Floresta da Tijuca, com } 8 \% \text {. }\end{array}$ \\
\hline $\begin{array}{l}\text { Parque Nacional } \\
\text { do Iguaçu }\end{array}$ & $\begin{array}{l}\text { Está localizado na região Extremo } \\
\text { Oeste Paranaense, a } 17 \mathrm{~km} \text { do centro } \\
\text { da cidade de Foz do Iguaçu, sob as } \\
\text { coordenadas lat. S. } 25^{\circ} 04^{4} \text { a } 25^{\circ} 41^{\prime} \text { e } \\
\text { long. W. } 53^{\circ} 58^{\prime} \text { a } 25^{\circ} 04^{\prime} \text {. O Parque } \\
\text { situa-se na bacia do rio Iguacu e } 14 \\
\text { municípios definidos pelo recorte } \\
\text { geográfico estão em raio de } 10 \mathrm{~km} \text { do } \\
\text { Parque. }\end{array}$ & $\begin{array}{l}185,26 \text { mil } \\
\text { hectares }\end{array}$ & 1939 & $\begin{array}{l}\text { O Parque permite a união, pelo Rio Iguaçu, ao } \\
\text { PN Iguazu, na Argentina, integrando-se ao } \\
\text { mais importante contínuo biológico do Centro- } \\
\text { Sul da América do Sul, e garantindo, com } \\
\text { aproximadamente } 600 \text { mil hectares de área } \\
\text { protegida, os esforços, dos dois países, sob } \\
\text { ações conjuntas, em proteger e conservar a } \\
\text { área. O PN tem como principal atração as } \\
\text { Cataratas do Iguaçu. Possui estrutura de } \\
\text { visitação para uso intensivo, contendo centro } \\
\text { de visitantes, diversas opções de trilhas. }\end{array}$ \\
\hline $\begin{array}{l}\text { Parque Nacional } \\
\text { de Jericoacoara }\end{array}$ & $\begin{array}{l}\text { Criado a partir da recategorização } \\
\text { parcial da Área de Proteção } \\
\text { Ambiental de Jericoacoara, o PN está } \\
\text { localizado nos municípios de Jijoca de } \\
\text { Jericoacoara, Cruz e Camocim, no } \\
\text { litoral cearense, sob as coordenadas } \\
2^{\circ} 47^{\prime} \mathrm{S} 40^{\circ} 30^{\prime} \mathrm{O} \text {. }\end{array}$ & $\begin{array}{l}8,85 \text { mil } \\
\text { hectares }\end{array}$ & 2002 & $\begin{array}{l}\text { O Parque possui trilhas, atrativos e setores } \\
\text { para esportes de vento. As praias } \\
\text { representam os principais atrativos, tais como } \\
\text { a Pedra Furada e o Serrote, que são formações } \\
\text { rochosas muito visitadas. O Parque apresenta } \\
\text { passeios nos manguezais e nas lagoas } \\
\text { temporárias. O Parque não possui Centro de } \\
\text { Visitantes. A Sede do Parque situa-se na Vila } \\
\text { de Jericoacoara. A Vila de Jericoacoara é } \\
\text { acessada por meio do município de Jijoca de } \\
\text { Jericoacoara, por trilhas não pavimentadas e } \\
\text { utilizando preferencialmente veículos de } \\
\text { tração integral e buggies. }\end{array}$ \\
\hline $\begin{array}{l}\text { Parque Nacional } \\
\text { Marinho de } \\
\text { Fernando de } \\
\text { Noronha }\end{array}$ & $\begin{array}{l}\text { Localiza-se no arquipélago de } \\
\text { Fernando de Noronha, a } 345 \mathrm{~km} \text { a } \\
\text { nordeste do cabo de São Roque, no Rio } \\
\text { Grande do Norte (RN) e } 545 \mathrm{~km} \text { de } \\
\text { Recife, no Pernambuco (PE), entre } \\
\text { as coordenadas geográficas } 3^{\circ} 45^{\prime} 3^{\circ} 56^{\prime} \\
\text { sul e } 32^{\circ} 20^{\prime} \text { oeste. Abrange } 70^{\prime} \% \text { da } \\
\text { ilha principal do Arquipélago } \\
\text { Fernando de Noronha e todas as } \\
\text { outras } 21 \text { ilhas secundárias, e sua } \\
\text { gestão ocorre em parceria com a Área } \\
\text { de Proteção Ambiental (APA) de } \\
\text { Fernando de Noronha. }\end{array}$ & $\begin{array}{l}11,27 \text { mil } \\
\text { hectares. }\end{array}$ & 1988 & $\begin{array}{l}\text { O Parque possui atrativos, trilhas, como a da } \\
\text { Baía do Sancho e a do Forte de São Joaquim, } \\
\text { sítios históricos divididos entre parte terrestre } \\
\text { e a parte marinha e um centro de visitantes. } \\
\text { Destaca-se as ilhas da Rata, Rasa e do Frade. } \\
\text { Em cada oportunidade, há possibilidade de } \\
\text { atividades de caminhada, observação da vida } \\
\text { marinha e escalada. Em alguns trechos } \\
\text { permite-se apenas passeios de barco, não } \\
\text { sendo permitido aos visitantes o fundeio. As } \\
\text { embarcações trafegam em velocidade } \\
\text { reduzida, e há fiscalização permanente. No } \\
\text { arquipélago, Há estrutura para serviços de } \\
\text { hospedagem, os quais atendem diversos tipos } \\
\text { de público. }\end{array}$ \\
\hline $\begin{array}{l}\text { Parque Nacional } \\
\text { de Brasília }\end{array}$ & $\begin{array}{l}\text { Situado na porção noroeste do } \\
\text { Distrito Federal (DF), a cerca de } 10 \\
\text { km do centro de Brasília entre as } \\
\text { coordenadas } 15^{\circ} 38^{\prime} 28^{\prime \prime} \text { Sul e } 48^{\circ} 1^{\prime} \\
\text { 15" Oeste. Sua criação está } \\
\text { diretamente relacionada com a } \\
\text { construção da Capital Federal, devido } \\
\text { ao convênio firmado entre o } \\
\text { Ministério da Agricultura e a NOVA } \\
\text { CAP - Companhia de } \\
\text { Desenvolvimento da Nova Capital, } \\
\text { para, entre outras tarefas, "propor e } \\
\text { criar novas reservas e postos } \\
\text { florestais" no Distrito Federal. } \\
\text { Abrange as regiôes administrativas } \\
\text { de Brasília, Sobradinho e Brazlândia } \\
\text { e o município goiano de Padre } \\
\text { Bernardo. }\end{array}$ & $\begin{array}{l}42,39 \mathrm{mil} \\
\text { hectares }\end{array}$ & 1961 & $\begin{array}{l}\text { O Parque possui diversas atividades de uso } \\
\text { público, em particular, o uso das piscinas da } \\
\text { "Água Mineral", terminologia utilizada pelo } \\
\text { público para identificar o Parque. Os locais } \\
\text { mais atrativos para o lazer no Parque são as } \\
\text { Piscinas, em especial a Piscina Velha. } \\
\text { Como atrativos, possui também o Centro de } \\
\text { Educação Ambiental e trilhas abertas para } \\
\text { caminhadas e passeios de bicicleta. O Parque } \\
\text { possui um centro de visitantes. }\end{array}$ \\
\hline
\end{tabular}

Fonte: BRASIL (1939; 1961; 1967; 2002); ICMBIO (2017b; 2019a; 2019b; 2019c; 2019d); IBAMA; FUNATURA (1990; 1998); ICMBIO; MMA (2008) e MEIRELLES et al., (2011). 


\begin{tabular}{|c|c|c|c|c|}
\hline $\begin{array}{l}\text { PARQUE } \\
\text { NACIONAL }\end{array}$ & $\begin{array}{l}\text { BREVE CARACTERIZAÇÃO E } \\
\text { LOCALIZAÇÃO GEOGRÁFICA }\end{array}$ & $\begin{array}{l}\text { ÁREA } \\
\text { TOTAL }\end{array}$ & $\begin{array}{l}\text { ANO DE } \\
\text { CRIAÇÃOO }\end{array}$ & $\begin{array}{l}\text { USO PÚBLICO E OPORTUNIDADES DE } \\
\text { VISITAÇÃO }\end{array}$ \\
\hline $\begin{array}{l}\text { Great Smoky } \\
\text { Mountains } \\
\text { National Park }\end{array}$ & $\begin{array}{l}\text { Localizado na região ocidental entre os } \\
\text { estados do Tennessee e da Carolina do } \\
\text { Norte, entre as coordenadas } 37^{\circ} 11^{\prime} 02^{\prime \prime} \mathrm{N} \\
\text { e } 108^{\circ} 29^{\prime} 19^{\prime \prime} \text { O, tornando-se uma das AP } \\
\text { mais extensas dos EUA. }\end{array}$ & $\begin{array}{l}203 \text { mil } \\
\text { hectares }\end{array}$ & 1934 & $\begin{array}{l}\text { Apresenta áreas para diversas atividades, } \\
\text { preserva } 160 \text { edifícios históricos e estruturas, } \\
\text { mantém } 25 \text { trilhas, distribuídas em mais de } 800 \\
\text { km, com diferentes características para } \\
\text { diversos públicos e atividades como ciclismo, } \\
\text { pescaria, caminhada, cavalgada, passeios em } \\
\text { cachoeiras e prédios históricos, e observação da } \\
\text { vida selvagem. Possui ainda um Centro de } \\
\text { Informações, três Centros de Visitantes, } \\
\text { Parques de Camping e diversas áreas para } \\
\text { alimentação, transporte e hospedagem. }\end{array}$ \\
\hline $\begin{array}{l}\text { Grand Canyon } \\
\text { National Park }\end{array}$ & $\begin{array}{l}\text { O PN está localizado na região } \\
\text { do Grand Canyon, no estado do Arizona, } \\
\text { entre as coordenadas geográficas } 36^{\circ} 6^{\prime} \\
3^{\prime \prime} \mathrm{N} \text { e } 112^{\circ} 5^{\prime} 26^{\prime \prime} \text { O. O Canyon, que } \\
\text { representa o nome do Parque, é um } \\
\text { desfiladeiro íngreme esculpido pelo rio } \\
\text { Colorado, com } 446 \mathrm{~km} \text { de comprimento, } \\
29 \mathrm{~km} \text { de largura e } 1,6 \mathrm{~km} \text { de } \\
\text { profundidade }\end{array}$ & $\begin{array}{l}492,6 \\
\text { mil } \\
\text { hectares }\end{array}$ & 1919 & $\begin{array}{l}\text { Possui dois setores, o "South Rim", ou Margem } \\
\text { Sul, que está aberto o ano inteiro para } \\
\text { visitantes e de onde é possível ter acesso ao } \\
\text { Desert View, Hermits Rest e do Grand Canyon } \\
\text { Village, um complex diferenciado com atrativos, } \\
\text { atividades e centro de transporte, e o "North } \\
\text { Rim", ou Margem Norte, que é menos acessível } \\
\text { e fica fechado para visitação durante o inverno } \\
\text { do hemisfério norte, entre maio e outubro. A } \\
\text { principal atração do Parque é o Grand Canyon, } \\
\text { o desfiladeiro que atrai milhões de visitantes. } \\
\text { Possui ainda três Centros de Visitantes, um } \\
\text { Museu, um Centro de Informações, e áreas de } \\
\text { visitação com serviços de hospedagem e } \\
\text { alimentação. }\end{array}$ \\
\hline $\begin{array}{l}\text { Zion National } \\
\text { Park }\end{array}$ & $\begin{array}{l}\text { Localizado no sudoeste do estado de } \\
\text { Utah, entre as coordenadas } 37^{\circ} 12^{\prime} 00.3^{\prime \prime} \\
\text { N e } 112^{\circ} 59^{\prime} 12.9^{\prime \prime} \text { O. Em } 31 \text { de julho de } \\
1909 \text {, o Presidente em exercício William } \\
\text { H. Taft emitiu a proclamação que } \\
\text { reservou } 15.200 \text { hectares como } \\
\text { Monumento Nacional Mukuntuweap. } \\
\text { Em 1918, outra proclamação } \\
\text { presidencial ampliou o monumento para } \\
31.080 \text { hectares. Em } 1919 \text {, o congresso } \\
\text { dos EUA estabeleceu a área em Parque } \\
\text { Nacional. Em } 1937 \text {, outro Monumento } \\
\text { Nacional, agora chamado de } \\
\text { KolobCanyons foi criado, e em } 1956, \text { o } \\
\text { congresso o acrescentou ao PN. }\end{array}$ & $\begin{array}{l}60,1 \mathrm{mil} \\
\text { hectares }\end{array}$ & 1919 & $\begin{array}{l}\text { Possui trilhas com diferentes tipos de acesso e } \\
\text { níveis de dificuldade e atrativos para } \\
\text { observação de aves e da vida selvagem. } \\
\text { Apresenta dois Centros de Visitantes, um } \\
\text { Museu de História Humana, áreas de Camping } \\
\text { e diversas opções de trilhas. Além disso } \\
\text { O Zion Lodge possui serviços turísticos de } \\
\text { hospedagem, lojas de presentes, correios e } \\
\text { alimentação. }\end{array}$ \\
\hline $\begin{array}{l}\text { Rocky } \\
\text { Mountain } \\
\text { National Park }\end{array}$ & $\begin{array}{l}\text { Localizado no estado do Colorado dos } \\
\text { EUA. A estrutura do Parque é dividida } \\
\text { em cinco regiões: Região 1, denominada } \\
\text { Lado Oeste; Região 2, Alpina, onde há } \\
\text { trilhas acessíveis e mirantes; Região 3, } \\
\text { Lado Norte; Região 4, porção mais } \\
\text { visitada, área central, com trilhas de } \\
\text { fácil acesso; e a Região 5, denominada } \\
\text { Lado Sul, onde localiza-se Estes } \\
\text { Park/LongsPeak, contém cachoeiras }\end{array}$ & $\begin{array}{l}107,55 \\
\text { mil } \\
\text { hectares }\end{array}$ & 1915 & $\begin{array}{l}\text { O Parque oferece atrativos e atividades } \\
\text { recreativas, como caminhadas, passeios } \\
\text { panorâmicos, observação da vida selvagem, } \\
\text { pesca, programas de educação ambiental e } \\
\text { passeios a cavalo. Oferece mais de } 130 \text { opções } \\
\text { de trilhas, ao longo de } 482 \mathrm{~km}^{2}, 5 \text { Áreas de } \\
\text { Camping; } 5 \text { Centros de Visitantes; } 1 \text { Centro de } \\
\text { Informações; } 1 \text { Museu Histórico. O Parque não } \\
\text { possui hotéis ou pousadas, apenas áreas de } \\
\text { camping. }\end{array}$ \\
\hline $\begin{array}{l}\text { Yosemite } \\
\text { National Park }\end{array}$ & $\begin{array}{l}\text { Localizado nas montanhas da Serra } \\
\text { Nevada, na Califórnia, EUA, nos } \\
\text { condados de Mariposa e Toulumne. }\end{array}$ & $\begin{array}{l}308,1 \\
\text { mil } \\
\text { hectares }\end{array}$ & 1890 & $\begin{array}{l}\text { O Parque oferece atrativos e atividades } \\
\text { distribuídos em } 2.600 \mathrm{~km} \text { de cursos d'água e } 560 \\
\mathrm{~km} \text { de estradas, além de } 1.300 \mathrm{~km} \text { em trilhas } \\
\text { abertas para visitação. Do total, } 18 \mathrm{~km}^{2} \\
\text { constitui-se do "Yosemite Valley", a atração } \\
\text { turística principal. }\end{array}$ \\
\hline
\end{tabular}

Fonte: NPS (2013); NPS (2014); NPS (2016); NPS (2019a); NPS (2019c); NPS (2019e); NPS (2020); SANTANA et al. (2016); USA (1864) e YOSEMITE (2019). 
Figura 1 - Mapa de localização dos PN pesquisados

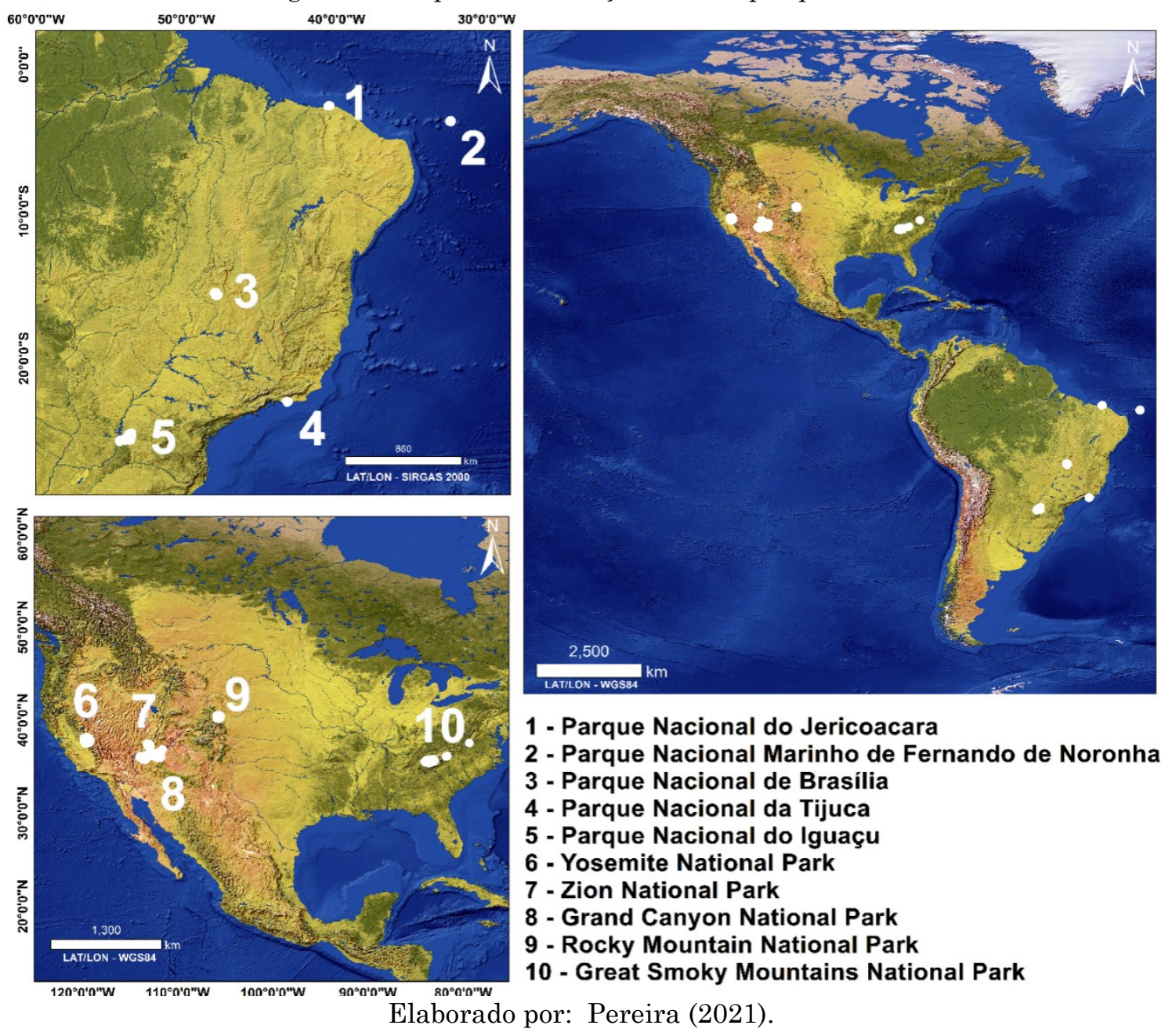

\section{Procedimentos Metodológicos}

O estudo foi conduzido pela abordagem qualitativa, com base na pesquisa bibliográfica e documental dos sites oficiais e planos de gestão (PRODANOV; FREITAS, 2013) com recorte temporal em 2017. Para obtenção dos dados foram utilizados os sites oficiais de cada Unidade e dos órgãos responsáveis pela gestão destes locais, sendo no Brasil, o Instituto Chico Mendes de Biodiversidade (ICMBIO) (CATARATAS DO IGUAÇU, 2019; ICMBIO, 2019a; ICMBIO, 2019b; ICMBIO, 2019c; ICMBIO, 2019d; ICMBIO, 2019e; PARQUE NACIONAL DA TIJUCA, 2019; PARQUE NACIONAL MARINHO DE FERNANDO DE NORONHA, 2019; PORTAL JERICOACOARA, 2019), e nos Estados Unidos, o National Park Service (NPS) (NPS, 2019a; NPS, 2019b; NPS, 2019c; NPS, 2019d; NPS, 2019e; ROCKY MOUNTAINS NATIONAL PARK, 2019).

Pesquisou-se nos documentos pertinentes, as características turísticas, as áreas de visitação, a estrutura e atrativos dos PN no Brasil (IBAMA; FUNATURA, 1990; IBAMA;
FUNATURA, 1998; ICMBIO; MMA, 2008; ICMBIO, 2011a; ICMBIO, 2017b; ICMBIO, 2018b) e nos Estados Unidos (NPS, 1976; NPS, 2001; NPS, 2004; NPS, 2007; NPS, 2010; NPS, 2014; NPS, 2016; NPS, 2017a; NPS, 2017b; NPS, 2017c; NPS, 2017d; NPS, 2018a; NPS, 2018b; NPS, 2018c; NPS, 2018d), possibilitando identificar informações a respeito do uso público e visitação para compreender o que as Unidades têm oferecido e como isso influencia a diversidade de opções que o visitante tem para a visita turística.

A análise das oportunidades foi realizada por meio doe método ROS (BROWN et al., 1978; CLARK; STANKEY, 1979; ORMSBY et al., 2004; BROWN et al., 2005; ICMBIO, 2011b; ICMBIO, 2018a), aplicado em estudos qualitativos anteriores (WALLACE, 2002; SOUZA; NORONHA-OLIVEIRA, 2012; BIRKEMOSE, 2015) para identificar as áreas específicas de recreação oferecidas nos $\mathrm{PN}$, permitindo a definição de um zoneamento de oportunidades recreativas, o qual é dividido em classes (LEE et al., 2013).

A pesquisa utiliza a matriz de cinco Classes 
de Oportunidades, sendo elas: Prístina, Primitiva, Natural, Rural e Urbana. Por meio de consulta direta à documentação, identificou-se e descreveu-se as oportunidades encontradas a partir de sua respectiva classe para verificar se os Parques possuem características que se enquadram em cada uma daquelas propostas pelo ROS (SOUZA; NORONHA-OLIVEIRA, 2012). Para compreendê-las, é apresentada no Quadro 3, a pergunta direta realizada por meio da análise documental e a relação entre as classes, seus atributos e a definição dos respectivos graus de intervenção.

É importante mencionar que a pesquisa não pretendeu realizar nenhuma abordagem comparativa entre os dois países, mas possibilitou visualizar, de maneira conjunta, se os PN mais visitados do Brasil e EUA oferecem aos seus visitantes um espectro de oportunidades de uso público.

Quadro 3 - Classes de Oportunidades de Visitação de acordo com grau de intervenção humana e seus atributos correspondentes

\begin{tabular}{|c|c|c|}
\hline $\begin{array}{c}\text { Classe de } \\
\text { oportunidade }\end{array}$ & Análise documental & Atributos da classe \\
\hline Prístina & $\begin{array}{l}\text { Há zonas reservadas com alto } \\
\text { grau de naturalidade; acesso } \\
\text { difícil; nenhuma infraestrutura } \\
\text { ou intervenção; pouca evidência } \\
\text { de atividade recreativa? } \\
\end{array}$ & $\begin{array}{l}\text { Visitação de Baixo Grau de Intervenção. Alto grau de naturalidade e } \\
\text { integridade dos processos ecológicos; pouca evidência de atividades } \\
\text { humanas e baixa probabilidade de encontros com outras pessoas. O } \\
\text { acesso é difícil, o nível de desafio e risco assumido pelo visitante é } \\
\text { alto; e é incomum a presença de estradas ou atividades motorizadas. }\end{array}$ \\
\hline Primitiva & $\begin{array}{l}\text { Há zonas de visitação, ainda com } \\
\text { alto grau de naturalidade, mas } \\
\text { possibilidade de acesso por } \\
\text { veículos, e estrutura mínima } \\
\text { para atividade turística? } \\
\end{array}$ & $\begin{array}{l}\text { Visitação de Médio Grau de Intervenção. Alto grau de naturalidade e } \\
\text { integridade dos processos ecológicos; pouca evidência de atividades } \\
\text { humanas. O acesso tem trilhas, as quais devem ser acompanhadas de } \\
\text { guias; muitos espaços sem trilhas demarcadas; pouca infraestrutura; } \\
\text { existe oportunidade para experimentar autonomia, solidão e desafios. }\end{array}$ \\
\hline Natural & $\begin{array}{l}\text { Há zonas com atividades } \\
\text { turísticas facilmente acessíveis, } \\
\text { trilhas demarcadas, } \\
\text { infraestrutura turística, e } \\
\text { presença de áreas de camping e } \\
\text { centro de visitantes? }\end{array}$ & $\begin{array}{l}\text { Visitação de Alto Grau de Intervenção. O ambiente tem } \\
\text { características naturais, e pode haver atividades humanas; a } \\
\text { paisagem tem atributos naturais e culturais; o acesso pode se dar de } \\
\text { forma motorizada ou a pé, por trilhas bem marcadas; os encontros e a } \\
\text { interação com outros visitantes são frequentes; a infraestrutura de } \\
\text { apoio está planejada para o uso intensivo de visitantes, com painéis e } \\
\text { placas informativas; permitindo trilhas autoguiadas. Nesta classe, } \\
\text { encontra-se centro de visitantes e áreas de camping. }\end{array}$ \\
\hline Rural & $\begin{array}{l}\text { Há zonas com comunidades } \\
\text { locais adjacentes à zona de } \\
\text { amortecimento, acessíveis por } \\
\text { estradas ou trilhas rurais, } \\
\text { possibilitando vivência com o } \\
\text { modo de vida local e interação } \\
\text { entre moradores e visitantes? }\end{array}$ & $\begin{array}{l}\text { Visitação de Alto Grau de Intervenção. Compreende áreas naturais e } \\
\text { assentamentos rurais adjacentes na zona de amortecimento da } \\
\text { unidade. O acesso se dá por estradas rurais e trilhas que conectam as } \\
\text { propriedades aos limites da unidade; pode haver oferta de serviços } \\
\text { para apreciar a cultura local, as práticas e o modo de vida da região. } \\
\text { Há possibilidade de interação entre a população local e visitantes. A } \\
\text { infraestrutura é geralmente simples e rústica. }\end{array}$ \\
\hline Urbana & $\begin{array}{l}\text { Há zonas com estrutura turística } \\
\text { comercial ou administrativa } \\
\text { desenvolvida; intervenções } \\
\text { visíveis, onde a presença } \\
\text { humana é predominante, } \\
\text { registrando-se, ainda, facilidades } \\
\text { para alimentação, } \\
\text { estacionamento e hospedagem? }\end{array}$ & $\begin{array}{c}\text { Visitação de Alto Grau de Intervenção. Ambiente caracterizado por } \\
\text { uma mescla de usos comerciais e turísticos; a área oferece serviços } \\
\text { para o turista, como transporte, hotéis, restaurantes variados, } \\
\text { hospitais e há encontros constantes com pessoas de diferentes } \\
\text { origens. }\end{array}$ \\
\hline
\end{tabular}

Fonte: Brown et al (2005); Souza e Noronha-Oliveira (2012); ICMBIO (2018a). Adaptado: os autores.

\section{RESULTADOS E DISCUSSÃO}

A partir da hipótese de que os $\mathrm{PN}$ mais visitados são os que oferecem mais oportunidades recreativas, o estudo inicialmente destaca que as taxas de visitação dos PN dos EUA são mais altas que dos PN do Brasil, uma vez que a soma nos cinco PN estadunidenses estudados representa cerca de cinco vezes mais visitantes que a soma dos cinco PN brasileiros (Tabela 1). Todavia, os dois PN brasileiros mais visitados, Tijuca e Iguaçu, representam $78 \%$ do total de visitantes dos $\mathrm{PN}$ brasileiros estudados, sendo que os outros três PN do ranking representam juntos cerca de $22 \%$.

Os Parques oferecem diferentes oportunidades distribuídas nas cinco classes (Quadros 4 e 5). Esse cenário aponta tendência de que os Parques mais visitados possuem mais oportunidades disponíveis, sugerindo existir relação entre o número de oportunidades recreativas oferecidas e o número de visitantes que o Parque passa a receber, tanto em relação aos brasileiros quanto aos estadunidenses (BROWN et al., 2005). A Figura 2 apresenta o espectro de oportunidades encontrado em cada país. 
Tabela 1 - Ranking de visitação dos Parques Nacionais brasileiros e estadunidenses em 2017.

Parques nacionais pesquisados

Visitas no ano de 2017

\begin{tabular}{|c|c|c|}
\hline \multirow{7}{*}{ 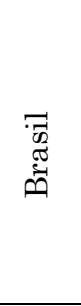 } & des nacionais pesquisados & e 2017 \\
\hline & Tijuca & 3.300 .000 \\
\hline & Iguaçu & 1.788 .922 \\
\hline & Jericoacoara & 780.000 \\
\hline & Marinho de Fernando de Noronha & 389.744 \\
\hline & Brasília & 265.518 \\
\hline & Total & 6.524 .184 \\
\hline \multirow{6}{*}{ 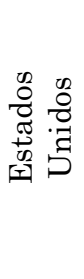 } & Great Smoky Mountains & 11.388 .893 \\
\hline & Grand Canyon & 6.254 .238 \\
\hline & Zion & 4.504 .812 \\
\hline & Rocky Mountain & 4.437 .215 \\
\hline & Yosemite & 4.336 .890 \\
\hline & Total & 30.922 .048 \\
\hline
\end{tabular}

Fonte: ICMBIO (2017a); NPS (2020); os autores (2019).

Quadro 4 - Oportunidades recreativas identificadas nos cinco PN brasileiros estudados e enquadradas nas cinco classes.

\begin{tabular}{|c|c|c|c|c|c|}
\hline \multirow{2}{*}{$\begin{array}{l}\text { PARQUES } \\
\text { NACIONAIS }\end{array}$} & \multicolumn{5}{|c|}{ CLASSES DE OPORTUNIDADES } \\
\hline & PRÍSTINA & PRIMITIVA & NATURAL & RURAL & URBANA \\
\hline TIJUCA & $\begin{array}{l}31 \text { áreas de } \\
\text { visitação ( } 50 \% \text { da } \\
\text { área do parque). }\end{array}$ & $\begin{array}{l}\text { Sete áreas de } \\
\text { visitação (locais } \\
\text { com trilhas de } \\
\text { acesso). }\end{array}$ & $\begin{array}{l}264 \text { áreas de } \\
\text { visitação. Um } \\
\text { centro de } \\
\text { visitantes; } 153 \\
\text { atrativos; } 128 \mathrm{~km} \\
\text { de trilhas. }\end{array}$ & $\begin{array}{l}\text { Três áreas de } \\
\text { visitação (locais de } \\
\text { acesso aos bairros } \\
\text { adjacentes ao } \\
\text { parque). }\end{array}$ & $\begin{array}{l}28 \text { áreas de } \\
\text { visitação (entre } \\
\text { restaurantes, } \\
\text { lanchonetes, áreas } \\
\text { para piquenique, } \\
\text { estacionamento e } \\
\text { loja de presentes). }\end{array}$ \\
\hline IGUAÇU & $\begin{array}{l}\text { Três áreas de } \\
\text { visitação ( } 60 \% \text { da } \\
\text { área do parque). }\end{array}$ & $\begin{array}{l}12 \text { áreas de } \\
\text { visitação (trilhas } \\
\text { primitivas). }\end{array}$ & $\begin{array}{l}\text { Nove áreas de } \\
\text { visitação (um } \\
\text { centro de } \\
\text { visitantes; quatro } \\
\text { trilhas principais; } \\
\text { cinco atrativos). }\end{array}$ & $\begin{array}{l}\text { Quatro áreas de } \\
\text { visitação (trilhas de } \\
\text { acesso aos } \\
\text { municípios } \\
\text { adjacentes). }\end{array}$ & $\begin{array}{l}\text { Três áreas de } \\
\text { visitação (estação } \\
\text { da administração, } \\
\text { estação espaço } \\
\text { porto canoa e praça } \\
\text { de alimentação). }\end{array}$ \\
\hline JERICOACOARA & - & $\begin{array}{l}\text { Quatro áreas de } \\
\text { visitação (trilhas } \\
\text { primitivas) }\end{array}$ & $\begin{array}{l}26 \text { áreas de } \\
\text { visitação (dois } \\
\text { setores para os } \\
\text { esportes de vento; } \\
17 \text { atrativos; sete } \\
\text { trilhas). Não possui } \\
\text { centro de } \\
\text { visitantes. }\end{array}$ & $\begin{array}{l}\text { Oito áreas de } \\
\text { visitação (trilhas de } \\
\text { acesso às vilas e } \\
\text { assentamentos } \\
\text { adjacentes ao limite } \\
\text { do parque). }\end{array}$ & $\begin{array}{l}\text { Quatro áreas de } \\
\text { visitação. } \\
\text { (portarias, com } \\
\text { guaritas para } \\
\text { controle do acesso e } \\
\text { registro de entrada } \\
\text { de visitantes). }\end{array}$ \\
\hline $\begin{array}{l}\text { FERNANDO DE } \\
\text { NORONHA }\end{array}$ & $\begin{array}{l}\text { Quatro áreas de } \\
\text { visitação } \\
\text { (monitoramento } \\
\text { e pesquisas } \\
\text { científica) }\end{array}$ & $\begin{array}{l}10 \text { áreas de } \\
\text { visitação (locais } \\
\text { de passeio de } \\
\text { barco). }\end{array}$ & $\begin{array}{l}34 \text { áreas de } \\
\text { visitação (oito } \\
\text { trilhas; } 19 \\
\text { atrativos; seis sítios } \\
\text { históricos; um } \\
\text { centro de } \\
\text { visitantes). }\end{array}$ & $\begin{array}{l}12 \text { áreas de } \\
\text { visitação (acesso às } \\
\text { vilas do entorno e } \\
\text { aos sítios } \\
\text { históricos). }\end{array}$ & $\begin{array}{l}\text { Cinco áreas de } \\
\text { visitação; } 102 \\
\text { opções de } \\
\text { hospedagem } \\
\text { apenas no } \\
\text { arquipélago. }\end{array}$ \\
\hline BRASÍLIA & $\begin{array}{l}\text { Quatro áreas de } \\
\text { visitação. } \\
\text { (pesquisa } \\
\text { científica) }\end{array}$ & $\begin{array}{l}15 \text { áreas de } \\
\text { visitação } \\
\text { (circundantes da } \\
\text { zona prístina). }\end{array}$ & $\begin{array}{l}\text { Sete áreas de } \\
\text { visitação (um } \\
\text { centro de } \\
\text { visitantes; trilhas e } \\
\text { atrativos). }\end{array}$ & $\begin{array}{l}\text { Duas áreas de } \\
\text { visitação. } \\
\text { Estradas de acesso } \\
\text { a municípios do } \\
\text { entorno }\end{array}$ & $\begin{array}{l}\text { Oito áreas de } \\
\text { visitação. } \\
\text { (restaurantes, } \\
\text { lanchonete, posto } \\
\text { médico, } \\
\text { bicicletário, posto } \\
\text { de apoio e sede). }\end{array}$ \\
\hline
\end{tabular}

Fonte: Os autores (2020). 
Quadro 5. Oportunidades recreativas identificadas nos cinco $P N$ estadunidenses estudados e enquadradas nas cinco classes.

\begin{tabular}{|c|c|c|c|c|c|}
\hline \multirow{2}{*}{$\begin{array}{l}\text { PARQUES } \\
\text { NACIONAIS }\end{array}$} & \multicolumn{5}{|c|}{ CLASSES DE OPORTUNIDADES } \\
\hline & PRÍSTINA & PRIMITIVA & NATURAL & RURAL & URBANA \\
\hline $\begin{array}{l}\text { GRAND } \\
\text { CANYON }\end{array}$ & $\begin{array}{l}\text { Nove áreas } \\
\text { de visitação. } \\
\text { (Rotas } \\
\text { "Wild" e } \\
\text { Áreas de } \\
\text { Pesquisa) }\end{array}$ & $\begin{array}{l}4 \text { áreas de } \\
\text { visitação } \\
\text { (Trilhas } \\
\text { primitivas). }\end{array}$ & $\begin{array}{l}21 \text { áreas de visitação } \\
\text { (Três Centros de } \\
\text { Visitantes; Um } \\
\text { Museu; Um Centro } \\
\text { de informações; } \\
\text { 11trilhas; Desert } \\
\text { View). }\end{array}$ & $\begin{array}{l}\text { Duas áreas de } \\
\text { visitação (Desert } \\
\text { View Drive e } \\
\text { acesso ao Grand } \\
\text { Canyon Village) } \\
\text { atividades e } \\
\text { centro de } \\
\text { transporte. }\end{array}$ & $\begin{array}{l}\text { Sete áreas de visitação. } \\
\text { Centro de Informações; } \\
\text { sanitários, } \\
\text { estacionamento, áreas } \\
\text { para piqueniques e } \\
\text { acesso a diversas } \\
\text { trilhas; hospedagem e } \\
\text { restaurantes; } \\
\text { Grand Canyon Lodge e } \\
\text { Grand Canyon Village }\end{array}$ \\
\hline ZION & $\begin{array}{l}\text { Uma área } \\
\text { de visitação } \\
\text { (Zion } \\
\text { Wilderness). }\end{array}$ & $\begin{array}{l}\text { Duas áreas de } \\
\text { visitação (Zion } \\
\text { Wilderness - } \\
\text { Backpacking; } \\
\text { Timber Creek } \\
\text { Overlook Trail). }\end{array}$ & $\begin{array}{l}24 \text { áreas de visitação } \\
\text { (Dois Centros de } \\
\text { Visitantes; Um } \\
\text { Museu; Três Áreas de } \\
\text { Camping; } 18 \text { trilhas). }\end{array}$ & $\begin{array}{l}1 \text { área de } \\
\text { visitação. Estrada } \\
\text { Sul - Acesso a } \\
\text { Cidade de } \\
\text { Springdale }\end{array}$ & $\begin{array}{l}4 \text { áreas de visitação } \\
\text { (áreas para alimentação } \\
\text { e hospedagem). Zion } \\
\text { Lodge (oportunidade } \\
\text { com inúmeros serviços } \\
\text { turísticos). }\end{array}$ \\
\hline $\begin{array}{l}\text { ROCKY } \\
\text { MOUNTAINS }\end{array}$ & $\begin{array}{l}\text { Três áreas } \\
\text { de visitação } \\
\text { (Specimen } \\
\text { Mountain, } \\
\text { West Creek } \\
\text { e Paradise } \\
\text { Park). }\end{array}$ & $\begin{array}{l}\text { Quatro áreas de } \\
\text { visitação(Bear } \\
\text { Lake, Wild } \\
\text { Basin, Longs } \\
\text { Peak, Agnes- } \\
\text { Vaille). }\end{array}$ & $\begin{array}{l}142 \text { áreas de } \\
\text { visitação (Cinco } \\
\text { Áreas de Camping; } \\
\text { Cinco Centros de } \\
\text { Visitantes; Um } \\
\text { Centro de } \\
\text { Informações; Um } \\
\text { Museu Histórico; } 130 \\
\text { trilhas). }\end{array}$ & $\begin{array}{l}\text { Quatro áreas de } \\
\text { visitação (Trilhas } \\
\text { com estrutura } \\
\text { turística de apoio } \\
\text { a duas estradas; } \\
\text { oferecem acesso } \\
\text { aos municípios do } \\
\text { entono (Grand } \\
\text { Lake e Estes } \\
\text { Park). }\end{array}$ & $\begin{array}{l}19 \text { áreas de visitação. } \\
\text { Ao contrário dos outros } \\
\text { Parques dos EUA } \\
\text { estudados, o Rocky } \\
\text { Mountain não possui } \\
\text { hotéis ou pousadas, } \\
\text { apenas áreas de } \\
\text { camping. }\end{array}$ \\
\hline YOSEMITE & - & $\begin{array}{l}\text { Duas áreas de } \\
\text { visitação } \\
\text { (Trilha Half } \\
\text { Dome e John } \\
\text { Muir). }\end{array}$ & $\begin{array}{l}22 \text { áreas de visitação } \\
\text { (Três Centros de } \\
\text { Visitantes; Um } \\
\text { Centro Wilderness; } \\
\text { Museu; Centro } \\
\text { Natural e de Arte; } \\
\text { Centro de } \\
\text { Conservação; Centro } \\
\text { de História de } \\
\text { Yosemite; Hill's } \\
\text { Studio; } 13 \text { áreas de } \\
\text { camping) }\end{array}$ & $\begin{array}{l}\text { Quatro áreas de } \\
\text { visitação } \\
\text { (Yosemite Valley; } \\
\text { Wawona Bosque } \\
\text { Mariposa; } \\
\text { Tuolumme } \\
\text { Meadows; e Tioga } \\
\text { Road)- possuem } \\
\text { comunidades } \\
\text { particulares que } \\
\text { oferecem práticas } \\
\text { de turismo. }\end{array}$ & $\begin{array}{l}15 \text { áreas de visitação } \\
\text { (locais de hospedagem, } \\
\text { serviços de } \\
\text { alimentação, áreas para } \\
\text { piquenique e sanitários) }\end{array}$ \\
\hline
\end{tabular}

Fonte: Os autores (2020).

Segundo alguns estudos (BROWN et al., 1978; CLARK; STANKEY, 1979; TAKAHASHI, 2004; BROWN et al., 2005; ICMBIO, 2011b; COELHO, 2015; ICMBIO, 2018a), para a aplicação da metodologia ROS não existe um único perfil de visitante, o que demanda diferentes oportunidades e ambientes para satisfazer um público diversificado. Neste sentido, cada ambiente, dentro da Área Protegida, é apto da combinação de diversas experiências, para diferentes tipos de visitantes. O espectro favorece essa diversidade a um nível adequado de proteção e utilização dos recursos e atrações turísticas. Todos os PN estudados possuem diversidade de experiências para turistas potenciais com suas diferentes expectativas.

É importante destacar que o ROS pode ser aplicado em qualquer Categoria de Manejo, não somente em Parques. Coelho et al. (2015) demonstram que o estabelecimento de zonas de recreação também em outras categorias de UC auxilia o planejamento e gestão da visitação. Definir normas de uso para cada local, delimitando regras de acesso e utilização, permitiu contribuir para a conservação na Reserva Particular do Patrimônio Natural (RPPN) Fazenda Cabeceira do Prata - Jardim (MS). O ROS é fundamental para regulamentar o uso público e o Plano de Gestão da Unidade. 
Figura 2 - Quantidade de oportunidades recreativas distribuídas nas cinco classes para cada PN analisado.

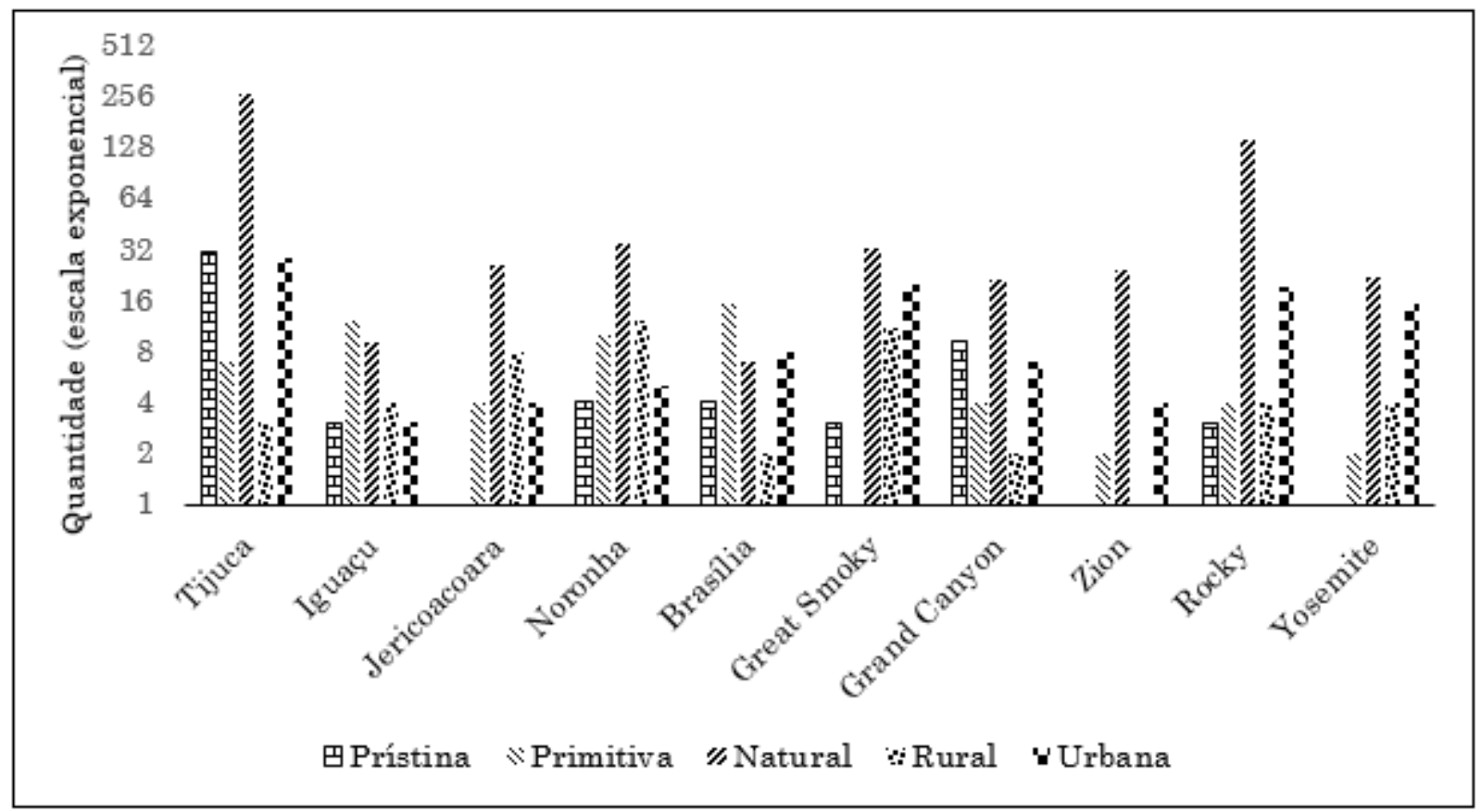

Fonte: Os autores (2020).

Nesta perspectiva, o presente estudo mostrou que os atributos naturais, sociais e de gestão, indispensáveis para a aplicação do espectro do ROS, são de significativa importância para administrar o uso turístico e recreativo dos visitantes. Sua importância relativa à organização, planejamento e gestão da recreação contribuem para definir e classificar o espectro de cada área estudada, uma vez que as cinco classes utilizadas no trabalho permitem fornecer objetivos e diretrizes para cada ambiente. Portanto, o ROS é de fato, ferramenta estratégica importante para o gerenciamento do uso dos visitantes.

\section{CONCLUSÕES}

A partir do gradiente de classes proposto pelo ROS, todos os PN estudados possuem as classes recreativas atrativas para demanda diversificada. Os Parques mais visitados de fato disponibilizam diferentes oportunidades para diversos tipos de turistas, fato que acontece tanto em PN brasileiros como em PN estadunidenses. Segundo a literatura, a diversidade de experiências e oportunidades oferecidas diferem significativamente na quantidade de visitantes na área.

Por outro lado, as taxas de visitação dos PN dos Estados Unidos representam cinco vezes mais que a soma dos cinco PN brasileiros, os quais enfrentam questões relacionados a diversidade de atrativos, trilhas e atividades disponíveis, efetividade de gestão, recursos humanos e investimentos, que reforçam a necessidade de ferramentas de planejamento, as quais sem elas, pode-se prejudicar o desenvolvimento turístico sustentável. Fica evidente, portanto, a urgência na mudança de paradigmas, comportamentos e políticas públicas relacionadas a conservação da natureza no Brasil.

É importante considerar que, a gestão da Unidade deve ser composta pelo conjunto total de atributos, incluindo condições de acesso, atividades, estrutura e serviços, aspectos que as UC brasileiras ainda necessitam melhorar. Apesar de cada ambiente dentro da AP ser apto a oferecer diversas experiências, o ROS preconiza que o rol de oportunidades deve ser complementado pelas oportunidades oferecidas também no entorno e nas demais áreas turísticas existentes na região, e não apenas dentro da área da UC. A visão do planejamento deve ser ampla e as oportunidades oferecidas devem ser compatíveis com a categoria e com os objetivos pré-estabelecidos.

As limitações na aplicação do ROS neste trabalho implicam no fato de que o método não preconiza a utilização de entrevistas com gestores de Áreas Protegidas ou aplicação de questionários com visitantes. Além disso, existe uma lacuna nos planos de gestão e documentos referentes à visitação turística dos Parques estudados. Apesar da lei brasileira indicar a elaboração do documento no prazo de cinco anos 
a partir da sua criação, muitos planos continuam antigos, desatualizados e utilizam dados secundários, sem padronizar ou normalizar a utilização de uma estrutura única para todas as UC. Neste sentido, a ferramenta ROS, pautada no zoneamento de oportunidades recreativas pode ser aplicado na elaboração de Planos de Gestão, como forma de organizar o uso público e turístico e potencializar o planejamento e a gestão, definindo regras adequadas para cada ambiente propício a receber visitantes.

\section{AGRADECIMENTOS}

Os autores agradecem a UFSJ pela concessão da bolsa de pós-graduação ao primeiro autor; ao Grupo de Pesquisa em Áreas Naturais Protegidas - IF SUDESTE-MG; ao Grupo Brasil Verde; e ao Professor Gabriel Pereira (UFSJ) pela assessoria cartográfica.

\section{REFERÊNCIAS}

BIRKEMOSE, M. Tourists perception of Recreational Opportunity Spectrum as a management tool in Fulufjället National Park. 2015. 64f. Dissertation (Master) - Norwegian University of Life Sciences, Norway, 2015. Disponível em: https://nmbu.brage.unit.no/nmbuxmlui/handle/11250/295847. Acesso em: 25 jan. 2019.

BRASIL. Decreto ${ }^{\circ} 1.035$, de 10 de janeiro de 1939. Cria o Parque Nacional do Iguassú e dá outras providências. Diário Oficial [da] República Federativa do Brasil. Brasília, DF, 1939. Disponível em: https://www2.camara.leg.br/legin/fed/declei/19301939/decreto-lei-1035-10-janeiro-1939-372797publicacaooriginal-1-pe.html. Acesso em: 15 set.2018.

BRASIL. Decreto n ${ }^{\circ}$ 241, de 29 de novembro de 1961. Cria o Parque Nacional de Brasília, no Distrito Federal, e dá outras providências. Diário Oficial [da] República Federativa do Brasil. Brasília, DF, 1961. Disponível em: http://www.planalto.gov.br/ccivil_03/decreto/histori cos/dcm/dcm241.html. Acesso em: 12 set.2018.

BRASIL. Decreto Federal n ${ }^{\circ} 60.183$ de 8 de fevereiro de 1967. Altera o nome do Parque Nacional do Rio de Janeiro, criado pelo Decreto $\mathrm{n}^{\circ} 50.923$, de 6 de julho de 1961, para Parque Nacional da Tijuca, com as dimensões e demais características previstas no presente Decreto, e dá outras providências. Diário Oficial [da] República Federativa do Brasil. Brasília, DF, 1967. Disponível em: https://www2.camara.leg.br/legin/fed/decret/19601969/decreto60183-8-fevereiro-1967-401706- publicacaooriginal-1-pe.html. Acesso em: 15 set. 2018.

BRASIL. Decreto $\mathrm{n}^{\circ}$ 96.693, de 14 de setembro de 1988. Cria o Parque Nacional Marinho de Fernando de Noronha e dá outras providências. Diário Oficial [da] República Federativa do Brasil. Brasília, DF, 1988. Disponível em: https://www2.camara.leg.br/legin/fed/decret/1988/d ecreto-96693-14-setembro-1988-447461-

publicacaooriginal-1-pe.html. Acesso em: 20 set. 2018.

BRASIL. Decreto $s / n^{\circ}$ de 4 de fevereiro de 2002. Cria o Parque Nacional de Jericoacoara, redefine os limites da Área de Proteção Ambiental de Jericoacoara, no Estado do Ceará, e dá outras providências. Diário Oficial [da] República Federativa do Brasil. Brasília, DF, 2002. Disponível em: https://www2.camara.leg.br/legin/fed/decret_sn/200 2/decreto-50767-4-fevereiro-2002-600357-

publicacaooriginal-122352-pe.html. Acesso em: 21 set. 2018

BROWN, P.; DRIVER, B. L.; MCCONNELL, C. The Opportunity Spectrum: Concept and Behavioral Information in Outdoor Recreation Resource Supply Inventories: Background and Application. Forest Management Faculty Publications. University of Montana, 1978. Disponível em: https://scholarworks.umt.edu/forest_pubs/31/.

Acesso em: 21 fev. 2019.

BROWN, P.; WALLACE, G.; NEWMAN, P.; WURZ, J.; LECHNER, L.; STOLL, D.; FINCHUM, R MCGLAUGLIN, W.; COURRAU, J.; BAUER, J.; VALENZUELA, F. ROVAP: el Rango de Oportunidades para Visitantes em Areas Protegidas. CIPAM/USDA, 2005.

CATARATAS DO IGUAÇU. Visite as Cataratas do Iguaçu [online]. 2019. Disponível em: https://cataratasdoiguacu.com.br/. Acesso em: 19 fev. 2019.

CLARK, R.N; STANKEY, G.H. The Recreation Opportunity Spectrum: a framework for planning, management and research. USDA: Forest Service Research Paper, 1979.

CNUC. Cadastro Nacional de Unidades de Conservação [online]. 2019. Disponível em: https://www.mma.gov.br/areas-

protegidas/cadastro-nacional-de-ucs. Acesso em: 15 nov. 2019

COELHO, M. DE F. O que Atrai o Turista? Gestão da Competitividade de Destinos a partir de Atrações e da Atratividade Turística. Revista Rosa dos Ventos Turismo e Hospitalidade, v. 7, n 4, 2015. p. 489505. https://doi.org/10.18226/21789061.v7iss4p489

CUNHA, C. P. SPINOLA, C. A. Parque Nacional: Um conceito com múltiplas interpretações. In: XIII SEPA - Seminário Estudantil de Produção Acadêmica, UNIFACS, 2014. Disponível em: https://revistas.unifacs.br/index.php/sepa/article/vi ew/3377. Acesso em: 18 fev. 2019.

DRIVER, B. L.; BROWN, P. J. The opportunity spectrum concept and behavioral information in outdoor recreation resource supply inventories: a rationale. Integrated inventories of renewable natural resources: proceedings of the 
workshop. Jan. 8-12, Arizona, 1978. Disponível em: https://agris.fao.org/agrissearch/search.do?recordID=US7896925. Acesso em: 14 fev. 2019.

DRUMMOND, J. A.; FRANCO, J. L. DE A.; OLIVEIRA, D. DE. Uma análise sobre a história e a situação das Unidades de Conservação no Brasil. In: GANEM, R. S. (org.). Conservação da biodiversidade: legislação e políticas públicas. Brasília, DF: Câmara dos Deputados, Edições Câmara, 2010. p.341-385. Disponível em: https://aprender.ead.unb.br/pluginfile.php/28053/m od_resource/content/1/Drummond_etal_2010_UC_1 egislacao_historico.pdf. Acesso em: 21 fev. 2019.

GOMES, C. R. Análise das oportunidades recreativas oferecidas em parques nacionais no Brasil e nos Estados Unidos. 2020, $143 \mathrm{f}$. Master Dissertation. Universidade Federal de São João del-Rei, São João del-Rei, 2020. Disponível em: https://ufsj.edu.br/portal2 -

repositorio/File/ppgeog/Carolina\%20Ribeiro\%20Go mes.pdf. Acesso em: 20 mar. 2020.

IBAMA; FUNATURA. Plano de Manejo do Parque Nacional Marinho de Fernando de Noronha. Brasília: Instituto Brasileiro do Meio Ambiente e dos Recursos Naturais Renováveis/ Fundação Prónatureza, 1990.253 p. Disponível em: https://issuu.com/projetogolfinhorotador/docs/_parn a_marinha_de_fernando_de_noron. Acesso em: 21 fev. 2019.

IBAMA; FUNATURA. Plano de Manejo do Parque Nacional de Brasília. Brasília: Instituto Brasileiro do Meio Ambiente e dos Recursos Naturais Renováveis/ Fundação Pró-natureza, 1998. 305p. Disponível

em:https://www.icmbio.gov.br/portal/images/stories /imgs-unidades-

coservacao/PARNA\%20Brasilia.pdf. Acesso em: 22 fev. 2019.

ICMBIO. Plano de Manejo do Parque Nacional de Jericoacoara. Brasília: Instituto Chico Mendes de Conservação da Biodiversidade, 2011a. 217p. Disponível em: https://www.icmbio.gov.br/portal/images/stories/im gs-unidades-coservacao/Contextualizacao.pdf. Acesso em: 18 fev. 2019.

ICMBIO. Roteiro Metodológico para Manejo de Impactos da Visitação com Enfoque na Experiência do Visitante e na Proteção dos Recursos Naturais e Culturais. Brasília: Instituto Chico Mendes de Conservação da Biodiversidade, 2011b. 88p. Disponível em: https://www.icmbio.gov.br/portal/images/stories/co municacao/roteiro_impacto.pdf. Acesso em: 28 set. 2018.

ICMBIO. Dados de Visitação 2007 - 2016. Instituto Chico Mendes da Biodiversidade, 2017a. Disponível em:

http://www.ICMBIO.gov.br/portal/images/stories/co municacao/noticias/2017/dados_de_visitacao_2012 2016.pdf. Acesso em: 24 set. 2017.

ICMBIO. Relatório Anual do Parque Nacional da Tijuca. Brasília: Instituto Chico Mendes de Conservação da Biodiversidade, 2017b. Disponível em:
http://Parquenacionaldatijuca.rio/files/report_anua 1_2017.pdf. Acesso em: 25 jan. 2019.

ICMBIO. Rol de Oportunidades de Visitação em Unidades de Conservação (ROVUC). In: CREMA, A.; FARIA, P. E. P. (orgs). Brasília: Instituto Chico Mendes de Conservação da Biodiversidade, 2018a, 43 p. Disponível em: https://www.icmbio.gov.br/portal/images/stories/edi tal/rovuc_rol_de_oportunidades_de_visitacao_em_u nidades_de_conservacao.pdf. Acesso em: 24 set. 2017.

ICMBIO. Plano de Manejo do Parque Nacional do Iguaçu. Brasília: Instituto Chico Mendes de Conservação da Biodiversidade, 2018b. 57p. Disponível em: https://www.icmbio.gov.br/portal/images/stories/pla no-de-

manejo/plano_de_manejo_do_parna_do_iguacu_fev ereiro_2018.pdf. Acesso em: 18 fev. 2019.

ICMBIO. Guia do Visitante - Parque Nacional da Tijuca [online]. 2019a. Disponível em: http://www.icmbio.gov.br/parnatijuca/guia-dovisitante.html. Acesso em: 12 fev. 2019.

ICMBIO. Guia do Visitante - Parque Nacional do Iguaçu [online]. 2019b. Disponível em: http://www.ICMBIO.gov.br/parnaiguacu/guia-dovisitante.html. Acesso em: 12 fev. 2019

ICMBIO. Parque Nacional de Brasília [online]. 2019c. Disponível

http://www.ICMBIO.gov.br/portal/visitacao1/unida des-abertas-a-visitacao/213-Parque-nacional-debrasilia.html. Acesso em: 12 fev. 2019.

ICMBIO. Parque Nacional de Jericoacoara [online]. 2019d. Disponível em: http://www.ICMBIO.gov.br/portal/visitacao1/unida des-abertas-a-visitacao/190-Parque-nacional-dejericoacoara.html. Acesso em: 12 fev. 2019.

ICMBIO. Parque Nacional Marinho de Fernando de Noronha [online]. 2019e. Disponível em: http://www.ICMBIO.gov.br/portal/visitacao1/unida des-abertas-a-visitacao/192-Parque-nacionalmarinho-fernando-de-noronha.html. Acesso em: 12 fev. 2019.

ICMBIO; MMA. Plano de Manejo do Parque Nacional da Tijuca. Brasília: Instituto Chico Mendes de Conservação da Biodiversidade/Ministério do Meio Ambiente, 2008. 1365p. Disponível em: https://www.icmbio.gov.br/portal/images/stories/doc s-planos-de-manejo/parna_tijuca_pm.pdf. Acesso em: 22 fev. 2019.

IUCN. Protected Area Categories. 2019. Disponível em: https://www.iucn.org/theme/protectedareas/about/protected-area-categories. Acesso em: 21 jan. 2019.

LEE, M.; BEARD, J.; THOMPSON, F. Recreation Opportunity Spectrum (ROS). 30 Slides. Northern Arizona University. Forest Service, Department of Agriculture, 2013. Disponível em: https://www.fs.usda.gov/Internet/FSE_DOCUMEN TS/stelprdb5412128.pdf. Acesso em: 12 fev. 2019.

MANNING, R.E. How much is too much? Carrying capacity of national parks and protected areas. In: Arnberger, A.; Brandenburg, C.; Muhar, A. (Ed.). Monitoring and management of visitor flows in recreational and protected areas. Conference 
Proceedings. Vienna: 2002. p.306-313. Disponível em: http://npshistory.com/publications/socialscience/how-much.pdf. Acesso em: 5 fev. 2019.

MEIRELLES, A. J. de A.; DANTAS, E. W. C.; DA SILVA, E. V. Parque Nacional de Jerioacoara: trilhas para a sustentabilidade. Fortaleza: Edições UFC, 2011, 157p. Disponível em:http://www.ppggeografia.ufc.br/images/livrojeri coacoaraii.pdf. Acesso em: 23 jan. 2019.

MENEGUEL, C.A, ETCHEBEHERE, M.L.C. Parques Nacionais no Brasil e a prática do turismo sustentável. Revista Hospitalidade, v.8, n.1, p.78-94, 2011. Disponível em: https://www.revhosp.org/hospitalidade/article/view/ 384/444. Acesso em: 22 jan. 2019.

NPS. Final Master Plan Rocky Mountain National Park. National Park Service, 1976. Disponível em: https://www.nps.gov/romo/learn/management/uplo ad/final_master_plan.pdf. Acesso em: 20 jan. 2019

NPS. Backcountry/Wilderness Management Plan and Environmental Assessment. Rocky Mountain National Park. National Park Service, 2001. Disponível

em:

https://winapps.umt.edu/winapps/media2/wilderne ss/toolboxes/documents/planning/ROMO\%20BWM P\%202001.pdf. Acesso em: 20 jan. 2019.

NPS. Grand Canyon National Park South Rim: visitor Study. LITTLEJOHN, M. A.; HOLLENHORST, S.J (orgs). National Park Service, 2004. 136p. Disponível em: https://www.coconino.az.gov/DocumentCenter/View /27890/2003-Grand-Canyon-NPS-Visitor-

Study?bidId=. Acesso em: 20 fev. 2019.

NPS. Widforss Trail. Grand Canyon National Park. National Park Service. 2007. Disponível em: https://www.nps.gov/grca/planyourvisit/upload/Wid fross.pdf. Acesso em: 20 jan. 2019.

NPS. Mapa y Guia Zion National Park. National Park Service. 2010. Disponível em: https://www.nps.gov/zion/planyourvisit/upload/Zion SpanishMG2010.pdf. Acesso em: 15 jan. 2019.

NPS. Foundation Document Zion National Park. National Park Service, 2013. Disponível em: https://www.nps.gov/zion/learn/management/uploa d/ZION_Foundation_Document_SP2.pdf. Acesso em: 16 fev. 2019.

NPS. Trail Map and Guide. Great Smoky Mountains National Park. National Park Service, 2014. Disponível em: https://www.nps.gov/grsm/planyourvisit/upload/GS MNP-Map_JUNE14-complete4-2.pdf. Acesso em: 26 may 2018.

NPS. Smokies Trip Planner Great Smoky Mountains National Park. National Park Service, 2016. Disponível em: https://www.nps.gov/grsm/planyourvisit/upload/20 16-trip-planner-w-map.pdf. Acesso em: 13 jun. 2018.

NPS. Desert View. Grand Canyon National Park. National Park Service. 2017a. Disponível em: https://www.nps.gov/grca/planyourvisit/upload/Des ert_View-b.pdf. Acesso em: 20 jan. 2019

NPS. Pocket Map: North Rim Services Guide. Grand Canyon National Park. National Park Service, 2017b. https://www.nps.gov/grca/learn/news/upload/nrpocket-map.pdf. Acesso em: 20 jan. 2019.

NPS. Pocket Map South Rim Services Guide. Grand Canyon National Park. National Park Service, 2017c. Disponível em: https://www.nps.gov/grca/learn/news/upload/srpocket-map.pdf. Acesso em: 20 jan. 2019

NPS. Visitor Use Management Plan. Zion National Park. National Park Service. 2017d. Disponível em: https://www.peer.org/assets/docs/nps/8_3_17_Zion_ preliminary_concepts.pdf. Acesso em: 03 fev. 2019.

NPS. Information Sheet Zion National Park. National Park Service. 2018a. Disponível em: https://www.nps.gov/zion/planyourvisit/upload/ZIO NSPRING2018TEAR.pdf. Acesso em: 04 fev. 2019.

NPS. Trip Planner (Planificador de Viaje). Grand Canyon National Park. National Park Service. 2018b. Disponível em: https://www.nps.gov/grca/learn/news/upload/grca_s panish.pdf. Acesso em: 04 fev. 2019.

NPS. Wilderness Guide Zion National Park. National Park Service. 2018c. Disponível em: https://www.nps.gov/zion/learn/news/upload/Wilder ness-Guide-2019-small.pdf. Acesso em: 04 fev. 2019.

NPS. Winter Information Sheet Zion National Park. National Park Service. 2018d. Disponível em: https://www.nps.gov/zion/learn/news/upload/WINT ER-TEAR-SHEET-2018-Updated2.pdf. Access: 04 fev. 2019.

NPS. Grand Canyon National Park. National Park Service. 2019a. Disponível em: https://www.nps.gov/grca/index.htm. Acesso em: 10 fev. 2019.

NPS. Great Smoky Mountains National Park. National Park Service. 2019b. Disponível em: https://www.nps.gov/grsm/index.htm. Acesso em: 10 fev. 2019.

NPS. Rocky Mountain National Park. National Park Service. 2019c. Disponível em: https://www.nps.gov/romo/index.htm. Acesso em: 23 fev. 2019.

NPS. Yosemite National Park. National Park Service. 2019d. Disponível em: https://www.nps.gov/yose/index.htm. Acesso em: 23 fev. 2019.

NPS. Zion National Park. National Park Service. 2019e. Disponível em: https://www.nps.gov/zion/index.htm. Acesso em: 21 fev. 2019.

NPS. National Park Service - Visitation Numbers.2020. Disponível em: https://www.nps.gov/aboutus/visitationnumbers.htm. Acesso em: 03 ago. 2020.

ORMSBY, J.; MOSCARDO, G.; PEARCE, P.; FOXLEE, J. A Review of Research into Tourist and Recreational Uses of Protected Natural Areas. Great Barrier Reef Marine Park Authority. Townsville, 2004. Disponível em: https://elibrary.gbrmpa.gov.au/jspui/retrieve/16d6b 09d-43ab-4914-bd04-f393e2b76f10/A-review-ofresearch-into-tourist-and-recreational-uses-ofprotected-natural-areas.pdf. Acesso em: $04 \mathrm{fev}$. 2019. 
PARQUE NACIONAL DA TIJUCA. 2019. Disponível em: http://www.Parquedatijuca.com.br/. Acesso em: 25 jan. 2019.

PARQUE NACIONAL MARINHO DE FERNANDO DE NORONHA. 2019. Disponível em: https://www.parnanoronha.com.br/. Acesso em: 04 fev. 2019.

PIRES, P.; RUGINE, V. Reconhecimento do Uso Público nos Parques Estaduais no Brasil com ênfase na visitação turística. Revista Brasileira De Ecoturismo, v. 11, $\mathrm{n}^{\circ} 1, \quad$ p.61-80, 2018. https://doi.org/10.34024/rbecotur.2018.v11.6667

PORTAL JERICOACOARA [online]. 2019. Disponível em:

http://www.portaljericoacoara.com.br/Parque_nacio nal_jericoacoara.html. Acesso em: 15 fev. 2019.

PRODANOV, C. C.; FREITAS, E. C. Metodologia do trabalho científico [electronic resource]: métodos e técnicas da pesquisa e do trabalho acadêmico 2 . ed. Novo Hamburgo: Feevale, 2013.

RECH, I.; PERELLO, L.; CANTO-SILVA, C. Panorama do Uso Público em Parques Estaduais do Rio Grande do Sul. Revista Brasileira De

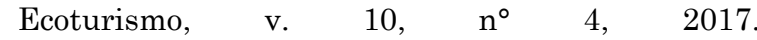
https://doi.org/10.34024/rbecotur.2017.v10.6657

ROCKY MOUNTAINS NATIONAL PARK. Vacation and Travel Information [online]. 2019. Disponível em: https://rockymountainnationalpark.com/. Acesso em: 15 abr. 2019.

SALVIO, G. M. M.; GOMES, C. R. Protected Area Systems in South American Countries. Floresta Ambiente. v. 25, n. 4, 2018. https://doi.org/10.1590/2179-8087.113417

SANTANA, R.C.B.; SILVA, H.P.; CARVALHO, R.M.C.M.O.; FRUTUOSO, M.N.M.A. A importância das Unidades de Conservação do Arquipélago de Fernando de Noronha. Holos, n.32, v. 7, p.15-31, 2016. https://doi.org/10.15628/holos.2016.4217

SOUZA, L.H.; NORONHA-OLIVEIRA, M.V. Zoneamento turístico em Áreas Naturais Protegidas: um diálogo entre conservação, oferta de atrativos e perfil da demanda ecoturística. Revista Brasileira de Ecoturismo, São Paulo, v.5, n.2, p.197-222. 2012.

https://doi.org/10.34024/rbecotur.2012.v5.6045

TAKAHASHI, L. Uso Público em unidades de conservação. Cadernos de Conservação. Fundação
O Boticário de Proteção à Natureza. Ano 2, n.2, 2004.

TERBORGH, J.; SCHAIK, C. V. Por que o mundo necessita de Parques. In: TERBORGH, J.; VAN SCHAIK, C.; DAVENPORT, L; RAO, M. (Orgs). Tornando os Parques Eficientes: estratégias para a conservação da natureza nos trópicos. Curitiba: Fundação O Boticário, 2002.

USA. Yosemite Act, June 30, 1864. An act authorizing a Grant to the State of California of the "Yosemite Valley," and of the land embracing the "Mariposa Big Tree Grove". United States of America Congress. District of Columbia, Washington, 1864. Disponível

em: https://www.nps.gov/yose/learn/management/enabl ing_leg.htm. Acesso em: 23 may 2019.

USA. Act $n^{\circ}$ 227, Fevruary 26, 1919. An Act To establish the Grand Canyon National Park in the State of Arizona. United States of America Congress. District of Columbia, Washington, 1919. Disponível

https://www.loc.gov/law/help/statutes-at-

large/65th-congress/session-3/c65s3ch44.pdf.

Acesso em: 20 may 2019.

WALLACE, G. Administração do visitante: lições do Parque Nacional de Galápagos. In: Lindberg, K.; Hawkings, D. (orgs). Ecoturismo: um guia para planejamento e gestão. São Paulo: SENAC. pp. 93-140, 2002.

YOSEMITE National Park established. 2019. Disponível em: https://www.history.com/this-dayinhistory/yosemite-national-park-established. Acesso em: 25 nov. 2019.

\section{CONTRIBUIÇÃO DOS AUTORES}

Carolina Ribeiro Gomes concebeu o estudo, analisou os dados e redigiu o texto. Múcio do Amaral Figueiredo orientou o estudo, analisou os dados, trabalhou na redação e revisão do texto Geraldo Majela Moraes Salvio co-orientou o estudo, analisou os dados, trabalhou na redação e revisão do texto. 